\title{
Educar para la vida: Un docente desde la pedagogía del amor ${ }^{1}$
}

Isidro Rodríguez Silva²

Todo sistema social humano se funda en el amor, en cualquiera de sus formas, que une a sus miembros, y el amor es la apertura de un espacio de existencia para el otro como ser humano.

Carlos Maturana.

\section{Resumen}

G ducar va más allá de una planificación curricular, de una docencia diaria, de una necesidad de conocer

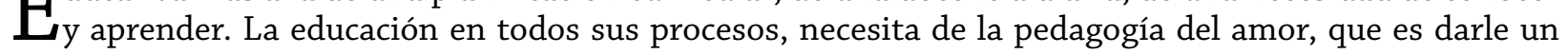
sentido humanístico al acto de educar. Todo quehacer educativo, toda acción docente, es y debe ser desde la pedagogía del amor.

La educación desde la pedagogía del amor es ver la naturaleza desde una ética ecológica, es interrelacionar naturaleza y literatura. Es percibir la literatura como otra expresión de la vida, para construir un pensamiento crítico y percibir un mundo cada día más armónico, un mudo donde la poesía, a como dice Vicente Aleixandre, tiene que ser humana, porque si no es humana, no es poesía. Pero, sobre todo, como dice el filósofo Tagore: «La poesía es el eco de la melodía del universo en el corazón de los humanos».

Amor y educación tiene que ver con llegar a ser seres humanos creativos, trasformadores; llegar al tipo de ser humano que anhelamos ser, mientras enseñamos y aprendemos. La única ley de todo educador es amar a sus educandos, donde la Mediación Pedagógica es aprendizaje significativo, integral, lúdico, placentero y bello.

Palabras Clave: pedagogía del amor; Mediación Pedagógica; labor docente.

\section{Summary}

Educating goes beyond a curricular planning, a daily teaching, or a need to know and learn. Education in all its processes needs of the pedagogy of love, which is to give a humanistic sense to the act of educating. Every educational activity, every teaching action, is and must be based upon the pedagogy of love.

Education from the pedagogy of love is to see nature from an ecological ethics, is to interrelate nature and literature. It is to perceive literature as another expression of life in order to build a critical thought and to perceive a more harmonious world, a world where poetry has to be human, as Vicente Aleixandre says, because if it is not human, it is not poetry. Moreover, as the philosopher Tagore states: "Poetry is the echo of the melody of the universe in the human hearts."

Love and education has to do with becoming creative and transformative human beings; to turn into the kind of human we long to be, as we teach and learn. The only law of every educator is to love their students, in which the Pedagogical Mediation is meaningful, integral, playful, pleasant and beautiful learning.

Keywords: Pedagogy of love; pedagogical mediation; teaching.

\footnotetext{
1 Ponencia efectuada en el auditorio de la Biblioteca de la URACCAN Recinto Nueva Guinea, el 11 de octubre del 2016.

2 Máster en Literatura Hispánica. Director de la revista Jaguarcolibrí, de Acción Creadora Intercultural (ACIC). Email:
} 


\section{Discurso sobre la pedagogía del amor}

T o primero que tenemos que redefinir es la conLceptualización socioeducativa del docente en relación con el devenir dinámico de la vida del siglo XXI, y preguntarnos: ¿Qué somos los maestros? Seguimos apostando que el docente es el apóstol de la educación, el abnegado de la enseñanza, el hombre o la mujer humilde que deja huellas en sus alumnos ¿Eso es lo que realmente somos? ¿Así nos sentimos, así actuamos y pensamos?

No creo que seamos apósteles, ni simplemente seres abnegados, ni los humildes que elaboramos planes de clases y cumplimos objetivos y temas cognitivos en función de aprendizajes y capacidades. Porque si usted se considera apóstol de la educación es, entonces, un ser pasivo que cumple con los programas de la asignatura que imparte, es usted un eufemista retórico, un árbol sin hojas, un educador sin visión, mucho menos misión de vida. Porque el docente que no educo para la vida, el educador que no se nutre de la pedagogía del amor no es un auténtico maestro.

El siglo XXI se caracteriza por una sociedad que ha sido afectada en todos los aspectos de su vida social; concentrada en la globalización que nos convierte, según Carlos Tünnermann, en una aldea planetaria; pero centrada, indiscutiblemente, por el conocimiento que nos lleva a una sociedad de la información, de la mundialización y de la civilización científica.

Si hablamos de un maestro que prepara a sus alumnos para la vida, debemos entonces ver nuestro entorno, lo que nos rodea, lo que vivimos, asumir nuestra realidad. La tierra está enferma asegura Leonardo Boff- en su libro Ecología: grito de la Tierra, grito de los pobres, pero ¿podemos hablar de Ciencias Naturales con nuestros alumnos, cuando los cálculos de estudios universitarios afirman que entre 1850 - 1950 se eliminó una especie por año, y que a partir de 1990 se elimina una especie por día? Vivimos el efecto de la era del cambio climático, la contaminación de las fuentes de agua y la destrucción de bosques y selvas tropicales. ¿Educamos para la vida cuando obviamos, que el problema más impactante del medio ambiente es la pobreza; donde más de 1,000 millones de personas viven en extrema miseria? Somos sociedades en crisis, que ha perdido su verdadero y auténtico sentido de vivir. Sólo educamos para la vida cuando el maestro habla de justicia ecológica, donde el ser humano es también una expresión biológica de la naturaleza.

Leonardo Boff, nos enseña a los maestros que la naturaleza está dentro de nosotros, que necesitamos un eco político educativo para llevar acabo estrategias de desarrollo sostenible, de una relación de amistad y respeto, entre nosotros y la naturaleza; necesitamos una ética ecológica con una relación de responsabilidad con nuestro planeta, que es nuestra casa, nuestro hogar.

La actual forma de concebir el conocimiento va más allá de la epistemología conocida, en ambos casos, sólo como una expresión en que se da el pensamiento o como una experiencia del ser humano. Hoy, el conocimiento científico nos lleva por la transformación tecnológica, a una era avanzada, donde el conocimiento mismo es una necesidad vital para poder vivir en las sociedades actuales, interconectadas e intercomunicadas.

Es por eso, que desde la educación, debemos dejar de enseñar el conocimiento desde conceptos tradicionales y dimensionarlo desde una educación aprendiente; esto significa que vivimos por el conocimiento, en una sociedad de aprendizajes significativos, que no sólo transforma el mundo natural, sino también que nos transforma a nosotros mismo. Es por eso que, desde la Mediación Pedagógica, el conocimiento nos lleva a ser aprendientes, innovadores, activos, creativos y competitivos frente a las exigencias del mundo contemporáneo.

Pero también, desde un conocimiento aprendiente nos lleva a una actitud solidaria; desde una educación con alumnos, cuya conducta asertiva nos involucre a todos. Solidaridad asertiva es cuando gana uno, pero también ganan todos; porque la actual era de la globalización y especialmente de la comunicación, nos permite una intrínseca relación de comunicación que se vuelve solidaria. Necesitamos una conducta y pensamiento fraterno, desde la educación, donde el conocimiento forje un pensamiento para la apropiación y transformación de la vida y la cultura.

Para que haya una sociedad aprendiente debe de haber un reencantamiento de la educación, como única opción de vida; creando hábitos de estudios, de experiencias entre conocimiento y aprendizaje, que nos lleve al logro de competencias; conocer e 
implementar nuevas herramientas tecnológicas de trabajo para una sociedad aprendiente. Las cuales permiten vincular diversos ambientes disciplinarios, teoría y práctica, conocimiento y experiencia en un contexto de innovación con mediaciones pedagógicas, a fin de propiciar un aprendizaje autónomo, reflexivo y consciente en la forma de pensar y actuar como sujetos de una sociedad cambiante. El conocimiento se vuelve imprescindible en una sociedad dinámica y solidaria, por medio de una educación transformadora.

En una nueva educación, el conocimiento debe de ir junto con el aprender, en un ambiente donde se organicen paralelamente como agentes y sistemas cognitivos, entendidos como sistemas basados en el conocimiento, tanto de los procesos naturales como sociales; donde se originan los procesos vitales de la educación. A como afirma Hugo Assmann: «La educación tendrá una función determinante en la creación de la sensibilidad social, necesaria para reorientar a la humanidad».

En su libro El placer y la ternura en la educación, Hugo Assmann nos dice que: «Los procesos cognitivos y vitales descubren su lugar de encuentro, marcado desde siempre en el centro de lo que es la vida, como proceso de auto organización, desde el plano biofísico hasta de los ámbitos sociales; la vida quiere seguir siendo vida -la vida que se gusta y que se ama- $\mathrm{y}$ anhela ampliarse en más vida».

La vida se gusta y se ama cuando es placentera; y si la sociedad es aprendiente, queremos una educación placentera que deje atrás aquella educación rígida, memorística, atrozmente disciplinada. Los cambios y las transformaciones en el saber y el ser deben estar ligadas en el placer. Una educación placentera significa, que cuando estamos aprendiendo nos sentimos felices, donde las actividades de la clase nos motivan al conocimiento y el aprendizaje, nos gusta y nos divierte.

El maestro debe prepararse y preparar a sus educandos para la comprensión e inserción en una educación llena de placer y ternura, como un acto comunicativo, con uno y con todos. Este placer en la educación nos junta en una solidaridad amorosa, en una pedagogía del amor, que nos lleva al placer por hacer, por actuar, por crear y experimentar; a como expresa el pedagogo costarricense Francisco Gutiérrez: «Educar por el goce significa movilizar las energías en una aventura, lúdica compartida, sentir y hacer sentir, participar entregando lo mejor de sí y recibiendo lo mejor de los otros».

Educar es amar, donde defino una estructura energética entre mis aprendientes que sienten placer de estar en clase; donde se vincula en una gran red educativa, el conocimiento, la práctica, la asertividad, la resilencia, todo en una resonancia educativa y pedagógica, que nos define, que nos prepara para ser seres nuevos, en busca de una sociedad nueva, sin exclusión, pero sobre todo sin pobreza.

Por eso, evolucionemos en una educación desde el paradigma del placer por educar, el amor y la ternura, me caracterizo como un ser educativo aprendiente, donde la educación se vincula con la vida; por tal motivo, la biopedagogía se vale del lenguaje, visto éste como un fenómeno de vida. Porque el lenguaje humano se debe a adaptaciones y evoluciones. El lenguaje nos hizo seres humanos, espirituales y amorosos. Pero también, el lenguaje tiene una función neurolingüística, donde cerebro y lenguaje se fusionan para percibir el mundo, la sociedad y el universo mismo.

El lenguaje humano se vale de la expresión de la poesía para cantarle a la vida, para ser una conciencia poética, y al mismo tiempo espiritual. La educación la concibe como una actitud poética, partiendo que la poesía es creación del lenguaje, para imaginar y soñar que somos seres sensibles y emotivos. Educar con la poesía es educar en el amor y la emotividad de vivir. El maestro debe de ser un poeta de la educación, donde nos unamos, a como dice Rubén Darío en su poema, Salutación del Optimista, en un solo haz de energía ecuménica.

La cultura produce la sociedad y la sociedad es una expresión misma de la cultura; ya que la palabra cultura viene del latín cultum y significa cultivar; $¿$ ¿Cultivar que? Cultivar a nuestros estudiantes a volver a nuestras raíces, que se nutren de nuestros valores, nuestras creencias y formas de conductas, porque no existen seres humanos incultos, todos poseemos una cultura, todo acto de vida es un acto cultural, donde la cultura es también las formas de educar y organizar la educación.

Un verdadero maestro hace, sobre todo, desarrollar las acciones de compartir y dar sentido a la vida, a la cultura, a la incertidumbre de nuestro tiempo. Darle sentido desde el goce de la vida, 
desde la significación de la cultura a la propuesta educativa, relacionada con mi experiencia de vida en la práctica pedagógica, promoviendo aprendizajes y competencias, donde todos impregnemos de sentidos en cada accionar, en cada ser y estar de nuestra vida, porque, a como afirma Francisco Gutiérrez: «Una educación con sentido educa, protagoniza seres para los cuales toda y cada una de las actividades, todos y cada uno de los proyectos, significa algo para la vida».

El sentido educativo que pasa a ser parte integral de la cultura, nos lleva de la incertidumbre, al gozo de la vida y de la expresión espiritual, nos guía a educar para convivir, después educar para apropiarnos de la historia y la cultura. La primera nos educa en convivencia, donde todo aprendizaje es un inter-aprendizaje, que nos traslada a la convivencia familiar, comunal, escolar y planetaria. La segunda, educándonos como seres históricos y culturales, porque somos producto de la historia y la cultura, dado que, nos dice Francisco Gutiérrez: «La escuela también es historia, como cualquier institución responde a los acontecimientos sociales, a una acumulación de formas, de percibir al hombre y de ubicarlo en este mundo».

La cultura se educa para la producción cultural, como dice el Dr. Francisco Gutiérrez, todo proceso cultural es educativo. Esto significa que sin la educación no hay cultura, porque el quehacer humano, sea este científico, tecnológico, místico o estético es todo un producto cultural.

La física cuántica, la entropía, por ejemplo, han determinado desde la ciencia, un producto cultural científico, que afecta la educación, como la vida misma. Así también en el plano estético, con la eco-poesía, que busca defender la vida de nuestro planeta a través de la palabra poética, es otra propuesta histórica y cultural de integrarnos en un todo a nuestra aldea planetaria.

La cultura, desde los centros educativos, la convertimos en una creación social, porque vivimos y compartimos una misma historia de vida, la cultura la hacemos y la aprendemos, para que sea una totalidad de nuestra existencia, donde cada parte tiene sentido en relación con un todo: educación, justicia, política, economía, arte, costumbres, creencias, entre muchas, que nos lleva una cosmovisión del mundo en que vivimos.
La cultura nos da identidad de lo que somos, porque tenemos raíces culturales, una de ellas es la identidad étnica, que además de la española, existe la garífuna, la lenca, la chortí, la misquita, la creole, mayagna y rama, para mencionar algunas. El maestro no sólo debe educar desde la cultura como una expresión vital de la vida; sino también, liberar el pensamiento de sus educandos del etnocentrismo, que es ver a la otra cultura con los lentes de nuestra propia cultura y posición social, donde sólo la nuestra es correcta y verdadera. Una lucha del maestro es contra la discriminación y el racismo.

El maestro no sólo debe luchar contra todo acto de aculturización, que borra nuestro rostro de identidad cultural, sino también por los derechos culturales, como: el derecho a la existencia, a la no discriminación, a la autodeterminación, a los derechos de los pueblos indígenas, el valor del respeto y la diversidad social. Debemos buscar nuevas relaciones entre escuela y cultura, que nos lleve a las necesidades de aprendizajes específicos de cada grupo de clase; también, la preocupación por el desarrollo de la autoestima y de una imagen y personalidad positiva, como una actitud tolerante y respetuosa frente a las diferencias.

¿Cuándo eliminaremos el mito de pensar que existe un divorcio entre política y educación? Un panorama a vuelo de pájaro en el mundo actual, donde los ejes transversales, ideológicos y la realización misma de todo actuar político, nos muestra una sociedad donde la pobreza ha incrementado considerablemente. Un aumento sustantivo en inseguridad social, no sólo en países donde hay guerra civil, como Siria; sino también sociedades que viven en supuesta paz, vemos grandes problemas de injusticias, del sistema penitenciario, de transporte y desempleo. La drogadicción, la violencia, la delincuencia, son otras formas de inseguridad más complejas que se han convertido en algo normal de nuestra vida actual.

Los desequilibrios ambientales y climáticos, ante la velocidad destructiva contra la naturaleza; la era de la información y la tecnología que nos trajo la globalización, ha llevado a la creciente pérdida de identidad cultural, y qué decir del materialismo, el consumismo, el individualismo, han afectado los valores éticos y morales.

Antes esta radiografía política del siglo actual, es imposible considerar que la educación está al margen de toda acción política, Francisco Gutiérrez 
lo determina cuando dice: «...por lo tanto, las relaciones entre educación y política son las que condicionan las características y las cualidades; las actividades y las opiniones; los procedimientos y la dimensión ética».

Desde la incertidumbre, el ser humano construye el mundo que lo rodea, a partir de la educación perfila sus sentidos éticos y espirituales. Desde la educación, las personas encuentran relación social, política, económica y cultural. Es desde una verdadera praxis política como realización educativa, que el estudiantado siendo sujeto social de cambio, logra su auto-aprendizaje; también su auto-estima, una visión crítica que lo conduce a ser un sujeto beligerante, propositivo y solidario, con capacidad de cambio y auto-transformación; la de un hombre nuevo con muchas virtudes en una sociedad de aprendizajes permanentes.

¿Tenemos que discutir de política en nuestros centros educativos? Efectivamente, la educación debe ser una discusión política, porque ahí se forja el futuro de la sociedad. En ella, se ordenan las oportunidades presentes y futuras de nuestras generaciones. Ahí también se distribuye el poder en la sociedad y se asignan los roles en la estructura social. Por eso, Francisco Gutiérrez en su libro, Educación y praxis política, determina que: «una educación como praxis política, es hacer, es robustecer la libertad de ser, de convivir; lo que significa mayor igualdad y democracia, por esta situación necesitamos no una escuela para la democracia, sino una escuela en democracia».

Las erradas políticas mundiales afectan también la educación y la escuela como expresión de ésta. Ante la destrucción del medio ambiente, la inequidad de género, la inseguridad ciudadana, es necesario la elaboración de un proyecto educativo, donde circule por sus venas esa praxis política y educativa. Entendemos por proyecto educativo: la transformación radical de los sistemas de enseñanza, de modo que posibilite la creación de una cultura alternativa, como la expresión de un hombre nuevo.

Educar con amor es educar para la vida, recordemos el poema Amo, amas de Rubén Darío, que dice: Amar, amar, amar, amar siempre, con todo/ el ser, y con la tierra y con el cielo, / con lo claro del sol, y lo oscuro del lodo,/ amar por toda ciencia y amar por todo anhelo. Sirva el poema como un pórtico necesario para un aprendizaje significativo, como una percepción diferente en el proceso hermoso de educar. Partiendo que nuestro cerebro no sólo es la fuente de nuestra mente y nuestra conciencia, sino también que con él percibimos el mundo, porque los sentidos están en los maravillosos pliegues del cerebro. Debemos educar con amor, porque en este sentimiento está contenido el todo de la vida, el amor es resonancia cósmica y universal.

Desde el discurso pedagógico del amor, entramos en una red de aprendizajes emotivos y sensitivos, de un humanismo constructivista, en un nuevo paradigma, para aprender para la vida con una educación con amor. Porque desde el cerebro, el universo está dentro de nosotros, con él creamos una imagen personal del mundo y desde nuestro corazón, están nuestros sentimientos por el planeta y por nosotros mismos.

La educación es un proceso de trasformación de vida conjunta, con una orientación definida por la manera de vivir de esa persona que actúa como padre o maestro. Todos somos, desde la cultura, una producción social, donde la educación es la panea sustancial de esta patria que estamos día a día, hombro a hombro, construyendo. Somos emociones y por lo tanto, el motor de la educación es el amor.

Un cambio en la educción es una educación con amor, que nos lleva a un trabajo en equipo amoroso, donde y desde el amor nos encamine a la creatividad, la calidad y acciones éticas, y éstas a las competencias ciudadanas y valores comprometidos en los cambios dentro de la escuela y afuera de ella. El que educa con amor se convierte en un verdadero líder, guía de la pedagogía del afecto, del corazón, de la ternura, del cariño, es decir, de lo que es la pedagogía del amor.

Educar en el amor es liberar al educando de su egoísmo personal y su yo competitivo e individual. Debemos promover seres competentes y competitivos en la solidaridad, el compañerismo, el respeto, la justicia, la búsqueda del bien común, que cuando gana uno ganan todos. La educación del amor va de la familia a la escuela y de la escuela al todo social y cultural.

Aprendamos amar y a sentir de acuerdo al espacio psíquico y espiritual, donde los seres humanos vivamos la Mediación Pedagógica por los caminos del amor, para que nos lleve a reflexionar, que la educación es un fundamento para desarrollar des- 
trezas emocionales en el educar. Eduquemos seres que sean amorosos con la vida misma.

La afectividad es la base firme de la educación, para muchos la educación es un recinto cerrado, cuyo candado es el corazón mismo del estudiante y cuya llave es el afecto sincero del maestro. En este sentido es importante ser afectuosos y amables con nuestros estudiantes. No debemos negarle ni una sonrisa. Una sonrisa es una flor en nuestros labios que ilumina el rostro de nuestros estudiantes.

Amar a los estudiantes es saber que tienen vida, emociones, intereses y voluntad propia igual que nosotros. No es cuestión de manipularlos como una cosa, según nuestros antojos, sino de apelar a sus sentimientos e intereses para crear en ellos la voluntad de que cooperen con nosotros mismos.

Las emociones como fundamento central de la visión humana, ya que define el espacio en que el razonar tiene validez, donde el amor es la emoción fundamental. La salud psíquica y fisiológica depende de su fundamento de la biología del amor, para romper todo sufrimiento y entrar en una relación de actitud amorosa.

Educar en la pedagogía del amor es convertir la ecología y el medio ambiente en una bifurcación mística del amor, donde hombre y naturaleza se abracen en un todo integral, en un holograma holístico, donde cada una de las partes, de los ecosistemas y la sociedad humana sea un todo, en una visión cósmica del mundo, del universo y de la vida. Es desde la naturaleza que vemos la vida, como un milagro que permite la existencia humana.

Desde la educación del amor la ecología no es sólo una ciencia de relaciones múltiples, sino principalmente de interés educativo y humanístico, porque todos estamos amenazados. Ya no existe un arca de Noé que nos salve de la destrucción, que nosotros mismos hemos provocado. La ecología plantea que la pobreza es nuestro mayor problema ambiental.

La ecología no debe ser, desde la educación, un problema de hombres y mujeres de ciencias o de grupos ambientalistas. Por lo tanto, desde el amor educativo debemos promover un mundo ecológico que ratifique la dignidad de la tierra, para salvar al planeta y a nosotros mismos, en un todo que sólo cabe en el inmenso e infinito corazón de Dios.
La Pedagogía del amor es también un acto cultural, educar desde la identidad cultural es crear otra forma de ser seres sociales. No existe cultura sin educación y educación sin una identidad cultural, donde medien los valores éticos y morales. La pedagogía del amor es también residencia de los ámbitos éticos, estéticos, cognitivos y espirituales.

Es por eso que desde la Pedagogía del amor necesitamos estudiantes con grandes capacidades, en la expresión, comprensión y comunicación, que les permita desarrollar la imaginación. La literatura nos ayuda a pensar, a disfrutar y aprender de la vida. La poesía o la narrativa desde la Mediación Pedagógica siempre nos realizan en nuestra condición humana.

Educar va más allá de una planificación curricular, de una docencia diaria, de una necesidad de conocer y aprender. La educación en todos sus procesos, necesita de la pedagogía del amor, que es darle un sentido humanístico al acto de educar. Todo quehacer educativo, toda acción docente, es y debe ser desde la pedagogía del amor.

La educación desde la pedagogía del amor es ver la naturaleza desde una ética ecológica, es interrelacionar naturaleza y literatura. Es percibir la literatura como otra expresión de la vida, para construir un pensamiento crítico, y percibir un mundo cada día más armónico, un mudo donde el poema, a como dice Vicente Aleixandre, tiene que ser humana, porque si no es humana, no es poesía. Pero, sobre todo, como dice el filósofo Tagore: «La poesía es el eco de la melodía del universo en el corazón de los humanos».

Amor y educación tiene que ver con llegar a ser seres humanos creativos, trasformadores; llegar al tipo de ser humano que anhelamos ser, mientras enseñamos y aprendemos. La única ley de todo educador es amar a sus educandos, donde la Mediación Pedagógica es aprendizaje significativo, integral, lúdico, placentero y bello. 